\title{
Estimation of Association between Healthcare System Efficiency and Policy Factors for Public Health
}

\author{
Seunggyu Lee ${ }^{1(1)}$ and Changhee Kim ${ }^{2, *(1)}$ \\ 1 School of Medicine, Sungkyunkwan University, Seoul 06351, Korea; lsg0619@skku.edu \\ 2 College of Business Administration, Incheon National University, Incheon 22012, Korea \\ * Correspondence: ckim@inu.ac.kr; Tel.: +82-835-8734
}

Received: 18 October 2018; Accepted: 12 December 2018; Published: 19 December 2018

\begin{abstract}
Objective: To assess the association between the healthcare system's efficiency and policy factors (the types of healthcare systems and various health policy indicators). Methods: In this study, a data envelopment analysis (DEA) with bootstrapping was applied to the healthcare system's efficiency to correct the bias of efficiency scores and to rank countries appropriately. We analyzed data mainly from the OECD (Organization for Economic Co-operation and Development) Health Data from 2014. After obtaining the efficiency score result, we analyzed which policy factor caused the inefficiency of the healthcare system by Tobit Regression. Results: Based on five types of healthcare system classification, the result suggested that the social health insurance (e.g., Austria, Germany, Switzerland) showed the lowest efficiency score on average when compared to other types of systems, but evidence of a statistically significant difference in healthcare efficiency among four types of healthcare systems was not found. It was shown that the pure technological efficiency of the healthcare system was negatively influenced by two main factors: user choice for basic insurance coverage and degree of decentralization to sub-national governments. Conclusions: Our findings suggest that countries with relatively low healthcare system efficiency may learn from countries that implement policies related to a low level of user choice and a high level of centralization to achieve more economical allocation of their healthcare resources.
\end{abstract}

Keywords: healthcare system efficiency (HSE); DEA bootstrap technique; Tobit model; health policy; OECD countries

\section{Introduction}

The world's healthcare system is changing. The United States initiated the 2010 Affordable Care Act (so-called Obama Care), which was formally launched in 2014. Germany also passed legislation on healthcare reform in 2010 to improve the profitability of health insurance and address high healthcare expenditure. In addition, countries like Brazil, Russia, India, China, and South Africa (BRICS) have recently made efforts to achieve universal health coverage [1]. As such, health care reform to improve people's standard of living is a major issue in many countries. However, there is still a lot of debate about how to change healthcare policy on issues of 'centralization versus decentralization' [2]. Furthermore, for example, whether to give patients a choice of healthcare provider or not is controversial among European countries even now [3,4]. Moreover, universal health coverage (UHC), which is nowadays a 'universal agreement', still has room for 'how' to achieve UHC considering the distinct context of each country [5]. For example, there is a case when a detailed plan for UHC is so unrealistic that it cannot address the financing need of a certain group [6]. It is therefore important to analyze which healthcare system is better and what policies have a positive impact on public health. 
According to Murray and Frenk [7], healthcare system performance is defined as what the system has achieved as an output relative to its potential for a given level of input. Meanwhile, Farrell [8] originally defined technical efficiency as the capability of yielding maximum output possible from a given set of inputs. Considering this logical equality between health system performance and technical efficiency, this paper used the term 'efficiency' as a synonym for the health system performance of a country. The quantified efficiency scores were obtained by data envelopment analysis (DEA), which is described in detail in the next section. This framework is referred to in [9].

Few studies have conducted an efficiency analysis of the healthcare system, particularly using frontier efficiency methodologies. According to Hollingsworth [10], who reviewed 317 studies on the productivity and efficiency of healthcare services, most studies $(52 \%)$ have focused on hospitals and only $4 \%$ of those studies were cross-country analyses dealing with the efficiency of the healthcare system. Even among those cross-country studies, some studies did not address what contributes to efficiency [11-14]. Only a few studies have paid attention to policy-related factors (e.g., institutional arrangement) as determinants of the efficiency of the healthcare system [15-17]. However, these studies used data before 2000 [15], applied a binary classification of healthcare systems [16], or the policy factors used were mostly expressed as dummy variables even though there were some variations in between [17].

Therefore, this study analyzed the efficiency of healthcare systems using the DEA technique and examined the relevance of efficiency with the type of healthcare system or health policy indicators. The goal of the study was to find out which healthcare system was more efficient and to analyze which policy factor contributed to the efficiency of the healthcare system based on these results.

\section{Materials and Methods}

\subsection{DEA Bootstrap Approach}

Data envelopment analysis (DEA), which is a non-parametric approach, analyzes the efficiency of groups (commonly referred to as decision-making units (DMUs)) with an idea that efficient DMU produces more output than others with the same amount of input [18]. DEA has an advantage in testing efficiency among other approaches such as stochastic frontier analysis (SFA) as it does not require any assumptions about the production frontier and is able to deal with complex systems that have multiple inputs and outputs such as a healthcare system [19]. Specifically, we used the variable return to scale (VRS) model proposed by Banker et al. [18] since the output (e.g., life expectancy) may not be proportionate with a change of input (e.g., health expenditure) due to the nature of the healthcare system.

DEA has been observed to be easily affected by the presence of outliers, especially with a small sample size [20]. Therefore, we introduced the bootstrapping approach [21] to improve the reliability of the efficiency estimates. For this approach, we repeated the re-sampling process and obtained efficiency estimates for many instances (e.g., 2000 times), then the result was approximated to the sampling distribution of the original estimates. That is, it was able to obtain bias-corrected efficiency estimates and confidence intervals by using the bootstrapping approach.

To get the bias-corrected efficiency scores, we obtained the standard DEA model to gain the efficiency score $\hat{\varnothing}_{k}(k=1,2,3, \cdots L)$ of individual DMUs. Additionally, we generated random samples in the size $L$ from standard DEA efficiency scores $\left\{\hat{\varnothing}_{k}(k=1,2,3, \cdots L)\right\}$ and applied kernel density estimation to obtain $\left\{\varnothing_{1 b}^{*}, \varnothing_{2 b}^{*}, \varnothing_{3 b}^{*}, \cdots \varnothing_{L b}^{*}\right\}$. Next, we calculated the pseudo dataset $\left\{\left(x_{k}, y_{k b}^{*}\right), k=1,2,3, \cdots L\right\}$ to generate RBT (reference bootstrap technology) and calculated the bootstrap efficiency score $\hat{\varnothing}_{k b}^{*}(k=1,2,3, \cdots L)$ of the standard DEA efficiency score $\hat{\varnothing}_{k}(k=1,2,3, \cdots L)$ of individual DMUs, finding the bootstrap corresponding to the model's values. Finally, in order to obtain the bootstrap mean value, it was repeatedly performed 2,000 times and the gap in the standard DEA efficiency score and bootstrap efficiency score was a bias score of this methodology. 


\subsection{Input/Output Selection}

The selection of input and output variables is important when applying the DEA method and should not include factors indiscriminately [20]. In addition, non-discretionary inputs can make the DEA model poorer [22]. It is also critical to identify the output variables that best describe the performance of the healthcare system and the input variables that can have a direct impact on these output variables. In previous studies, Retzlaff-Roberts et al. [14], who measured the efficiency of healthcare systems in OECD countries, chose infant mortality and life expectancy as the output variables. A relatively recent study, Hadad et al. [17] selected the physician density, inpatient bed density, health expenditure per capita, gross domestic product (GDP) per capita, and the consumption of fruit and vegetables per capita as input variables, and life expectancy at birth and infant survival rate were selected as output variables. Similarly, Asandului et al. [23] set the number of doctors, number of hospital beds, and public health expenditures as input variables, and life expectancy at birth, health adjusted life expectancy, and infant mortality rate as output variables. In this study, we chose expenditure on health per capita, practicing physicians per capita, and the number of beds per capita as input variables, and infant survival rate and life expectancy as output variables. There are several more factors related to the performance of the healthcare system such as cost sensitivity (e.g., cost sensitivity of healthcare consumers for general health care [24]), but those were not taken into account due to the availability of data on a global scale.

The expenditure on health per capita has been considered as a major factor that is highly associated with health outcomes such as infant mortality and life expectancy $[25,26]$. On the other hand, the number of practicing physicians and beds per capita is one of the representative indicators that show the level of public health infrastructure of the country. In particular, the shortage of inpatient hospital beds can lead to emergency department overcrowding that may be a threat to public health [27]. The number of practicing physicians and beds per capita has also been widely used in studies with DEA models [17,23].

Since subjective health outcomes such as healthcare satisfaction are not easy to quantify, the objective health outcomes such as life expectancy and infant mortality rate have been widely used in healthcare system efficiency studies $[14,17,23]$. Due to the assumption of DEA that more output is better, the infant mortality rate (IMR) of the OECD is not suitable as an output variable. Therefore, referring to the study of Afonso and Aubyn [28] and Hadad et al. [17], IMR was transformed to the infant survival rate (ISR $=(1000-$ IMR $) /$ IMR $)$. This can be interpreted as the proportion of surviving infants compared to the number of children that died in the first year of life, a high level of which means better healthcare status.

\subsection{Five Types of Healthcare System}

Bohm et al. [29] classified 29 OECD countries into five healthcare systems, with a more detailed classification compared to the classification of three healthcare systems by the OECD [30]. The five types of OECD healthcare systems are distinguished by which type of actors (state, societal, and private actors) dominates each core dimension (regulation, financing, and service provision) of the healthcare system. They also argued that these three dimensions had a hierarchy where regulation leads, financing follows, and service provision comes last. Although we could think of up to 27 (three actors raised to the power of three dimensions) types of healthcare systems, they found that the 29 OECD countries could be classified into only five types of healthcare systems: National Health Service (NHS), the National Health Insurance (NHI), the Social Health Insurance (SHI), the Etatist Social Health Insurance (ESHI), and the Private Health System (PHS). The classification of the 29 OECD countries is presented in Table 1. 
Table 1. Classification of the OECD healthcare systems (Chile, Greece, Latvia, Mexico, Slovenia, and Turkey are missing due to lack of data). Source: Bohm et al. [29].

\begin{tabular}{ccccl}
\hline Type & Regulation & Financing & Provision & \multicolumn{1}{c}{ Countries } \\
\hline NHS & State & State & State & Denmark, Finland, Iceland, Norway, Sweden, Portugal, Spain, UK \\
NHI & State & State & Private & Australia, Canada, Ireland, New Zealand, Italy \\
SHI & Societal & Societal & Private & Austria, Germany, Luxembourg, Switzerland \\
PHS & Private & Private & Private & USA \\
ESHI & State & Societal & Private & Belgium, Estonia, France, Czech Republic, Hungary, the \\
& & & Netherlands, Poland, Slovakia, Israel, Japan, Korea \\
\hline
\end{tabular}

According to Bohm et al. [29], under the NHS type, all three core dimensions (regulation, financing, and service provision) are thoroughly controlled by the state. On the other hand, the NHI system is where only service provision sector is in charge of private (for-profit) actors. The SHI system is where all dimensions are dominated by societal (non-profit) actors, while the PHS type is where private actors are in charge of regulation, financing (e.g., private insurance), and service provision. The ESHI system is where the state dominates the regulatory sector and allows authority for financing to societal actors for the service provision to private actors. We assumed that there must be some differences in terms of efficiency according to the five healthcare system categories. Therefore, we used the $t$-test to examine whether the difference was statistically significant.

\subsection{Mann-Whitney U Test and Tobit Regression Model}

We assumed that the difference mainly originated from policy factors (microscopic) that are highly influenced by its healthcare system (macroscopic). Therefore, we introduced ten healthcare policy indicators categorized by Joumard et al. [31] and used them to determine the microscopic causes of differences in efficiency. DEA is a representative non-parametric methodology to estimate the relative efficiency score. Therefore, we could not apply the t-test since this method does not comply with normal distribution. In this sense, the Mann-Whitney $U$ test is conducted to verify that a statistically significant difference existed between the two independent groups. In this study, countries were divided into two groups by the median efficiency, and then the Mann-Whitney U test was used to confirm whether there was a difference in the score of the policy indicators between the two groups. Next, we chose three policy indicators that showed a significant difference between the two groups. After that, policy indicators with significant differences were selected as an independent variable, and the DEA efficiency score was selected as a dependent variable, and the influence of the corresponding policy index was analyzed through regression analysis. Since the DEA efficiency score was truncated from zero to one, the ordinary least square (OLS) regression resulted in biased and inconsistent results [32]. Additionally, the Tobit Regression Model was used when the dependent variables (efficiency score of each DMU) were bounded from above, below, or both. Therefore, the Tobit regression model was introduced in this study.

The formula of the general Tobit regression model is as follows:

$$
\begin{gathered}
\begin{cases}Y_{t}=X_{t} \beta+\mu_{t} & \text { if } X_{t} \beta+\mu_{t}>0 \\
0 \quad & \text { if } X_{t} \beta+\mu_{t} \leq 0,\end{cases} \\
t=1,2, \ldots, N
\end{gathered}
$$

where $Y_{t}$ is the dependent variable; $X_{t}$ is the independent variable vector; $\beta$ is the unknown coefficients; and $\mu_{\mathrm{t}}$ is the independent distribution error assumed to be a normal distribution with an average of zero.

The efficiency score in this study can be defined as follows:

$$
\mathrm{E}_{\mathrm{i}}=\alpha+\beta_{1} \mathrm{UCI}+\beta_{2} \mathrm{UI}+\beta_{3} \mathrm{DC}+\mu_{\mathrm{i}}
$$


where $E_{\mathrm{i}}$ represents the efficiency score; UCI, UI, DC are the three policy factors used as independent variables (each abbreviation represents user choice of insurers, user information, and decentralization); $i$ represents the number of countries; $\alpha$ represents a constant; and $\mu_{i}$ represents an error term. We chose these three factors (UCI, UI, and DC) to find the effect of policy factors on the efficiency of the healthcare system. First, UCI was selected for the basic insurance coverage and UI was selected for the quality on prices of various healthcare systems. Finally, DC was chosen to estimate the effect of decentralization on sub-national governments. More specific information about how these three policy factors were selected are described in Section 3.

\subsection{Data}

OECD Health Data 2014 were used as input and output variable data. In the case of blank data, we used the estimated values from the OECD Health Data 2013 and OECD Health Data 2015 or supplemented them with the WHO Global Health Observatory data.

The policy indicator data to be used potentially in the Tobit regression analysis were data from OECD's Joumard et al. [31], which quantified 20 health indicators with values between 0.0 and 6.0. Ten indicators were selected, except for those showing a significantly smaller standard deviation or a correlation with other indicators. In particular, among the healthcare policy indicators, coverage area and policy size and depth have very low standard deviations and are excluded as independent variables. OECD countries seem to be similar in coverage area, extent, and depth to which coverage area and policy are applied. Note that the DEA efficiency was evaluated for all 35 OECD countries, but 29 countries (excluding Chile, Greece, Latvia, Mexico, Slovenia and Turkey from 35 countries) were classified according to Bohm et al.'s [29] scheme for comparing efficiency differences. However, 29 different countries (excluding Chile, Estonia, Israel, Latvia, Slovenia, and United States from 35 countries) were included in the Tobit regression model due to the availability of health policy indicator data.

\section{Results}

The efficiency score of 35 countries derived from bootstrapped DEA (Table 2) was 0.7802 on average and the standard deviation was 0.1259. It shows that Luxembourg, Greece, and Israel had the highest healthcare system efficiency and Germany, Austria, and the Slovak Republic had the lowest efficiency. Luxembourg has a relatively low practicing physicians per capita $(2.86,23 \mathrm{rd})$, but showed relatively high infant survival rate $(356.14,9$ th) and life expectancy $(85.2,6$ th). Germany, on the other hand, injected the sixth highest health care expenditure (5200.1) and the third highest number of hospital beds (8.23), but its average life expectancy (83.6) and infant survival rate (311.50) were similar to the average $(83.34,302.21)$.

Mean and standard deviations of efficiency scores were compared to determine if there was a difference in efficiency depending on the type of healthcare system. The results are shown in Table 3. Note that the case of the PHS to which the US belongs and the social-based mixed-type to which Slovenia belongs were excluded because of the lack of samples.

Comparing the average value of efficiency by healthcare system shows that the health care efficiency of the Social Health Insurance system was remarkably low. Especially when compared to the National Health Service system, we could see a large difference in the efficiency score of 0.1911. However, it showed no significant difference between the four types of systems (except PHS due to lack of data) as a result of a one-way ANOVA (analysis of variance) test at the 0.05 significant level $(p=0.1157)$.

Regression analysis was conducted to confirm whether the difference in efficiency was caused by the difference in health policy. Among the health policy indicators, Joumard et al. [31] presented, ten indicators were selected as potential factors. However, it may distort the causal relationship between variables if many indicators were used as independent variables in the regression analysis [33]. Peduzzi [34] noted that for logistic regression analysis, the number of events per predictive variables 
less than 10 could cause major problems regarding the biases. Considering that this restriction can be slightly relaxed in most cases [35], we decided to select up three independent variables.

Table 2. Efficiency scores (bias-corrected, original), bias, standard deviation (SD) of 35 OECD countries.

\begin{tabular}{|c|c|c|c|c|}
\hline DMU & Score (Bias-Corrected) & Bias & Score (Original) & SD \\
\hline Luxembourg & 0.9249 & 0.0505 & 0.9754 & 0.0361 \\
\hline Greece & 0.9142 & 0.0858 & 1.0000 & 0.0597 \\
\hline Israel & 0.9140 & 0.0468 & 0.9608 & 0.0315 \\
\hline Estonia & 0.9135 & 0.0865 & 1.0000 & 0.0712 \\
\hline France & 0.9094 & 0.0706 & 0.9799 & 0.0700 \\
\hline Portugal & 0.9093 & 0.0536 & 0.9629 & 0.0382 \\
\hline Latvia & 0.8948 & 0.1052 & 1.0000 & 0.0769 \\
\hline Ireland & 0.8853 & 0.0448 & 0.9301 & 0.0299 \\
\hline Iceland & 0.8792 & 0.1208 & 1.0000 & 0.1135 \\
\hline Poland & 0.8762 & 0.0606 & 0.9368 & 0.0439 \\
\hline Sweden & 0.8586 & 0.1414 & 1.0000 & 0.1289 \\
\hline Korea & 0.8577 & 0.1423 & 1.0000 & 0.1198 \\
\hline Canada & 0.8545 & 0.0489 & 0.9034 & 0.0360 \\
\hline Italy & 0.8469 & 0.0749 & 0.9218 & 0.0968 \\
\hline Turkey & 0.8321 & 0.1679 & 1.0000 & 0.1600 \\
\hline Mexico & 0.8101 & 0.1899 & 1.0000 & 0.2017 \\
\hline Chile & 0.7970 & 0.2030 & 1.0000 & 0.2461 \\
\hline Denmark & 0.7957 & 0.0353 & 0.8309 & 0.0239 \\
\hline New Zealand & 0.7939 & 0.0418 & 0.8357 & 0.0315 \\
\hline Spain & 0.7899 & 0.2101 & 1.0000 & 0.2748 \\
\hline United Kingdom & 0.7892 & 0.0478 & 0.8370 & 0.0331 \\
\hline Slovenia & 0.7863 & 0.2137 & 1.0000 & 0.2710 \\
\hline Japan & 0.7824 & 0.2176 & 1.0000 & 0.2816 \\
\hline Finland & 0.7786 & 0.0593 & 0.8380 & 0.0653 \\
\hline Czech Republic & 0.7593 & 0.0616 & 0.8209 & 0.0657 \\
\hline Norway & 0.7139 & 0.0378 & 0.7517 & 0.0347 \\
\hline Hungary & 0.7099 & 0.0323 & 0.7423 & 0.0234 \\
\hline Switzerland & 0.7029 & 0.0436 & 0.7465 & 0.0423 \\
\hline Australia & 0.6973 & 0.0407 & 0.7380 & 0.0313 \\
\hline United States & 0.6722 & 0.0499 & 0.7222 & 0.0415 \\
\hline Belgium & 0.6189 & 0.0356 & 0.6545 & 0.0257 \\
\hline The Netherlands & 0.5926 & 0.0315 & 0.6241 & 0.0221 \\
\hline Slovak Republic & 0.5805 & 0.0398 & 0.6203 & 0.0375 \\
\hline Austria & 0.4412 & 0.0313 & 0.4725 & 0.0226 \\
\hline Germany & 0.4240 & 0.0348 & 0.4589 & 0.0280 \\
\hline
\end{tabular}

Table 3. The types of healthcare system: number of countries, mean efficiency score, and standard deviation of efficiency score.

\begin{tabular}{ccccc}
\hline Type & NHS & NHI & SHI & ESHI \\
\hline $\mathrm{N}$ & 8 & 5 & 4 & 11 \\
Efficiency Mean & 0.8143 & 0.8156 & 0.6232 & 0.7740 \\
Efficiency SD & 0.0634 & 0.0738 & 0.2381 & 0.1318 \\
\hline
\end{tabular}

Before the regression analysis, we tried to derive some policy indicators that showed a significant difference in the relatively efficient group and others. To do this, we divided the efficient and inefficient countries based on the median of the efficiency scores and verified whether there was a difference in the score of the policy indicators between the two groups using the Mann-Whitney $U$ test. The results are shown in Table 4. User information (on the quality on prices of various health care services), and decentralization (to sub-national governments) was equal to or less than 0.05 in $p$ value, which means that the two policy indicators between the two group showed a significant difference. User choice of insurers (for basic insurance coverage) showed a marginal significance ( $p=0.053$ ). 
Therefore, three factors that showed the lowest $p$ values in order were selected as independent variables of the Tobit regression model presented as Equation (2) in Section 2.4.

Table 4. Mann-Whitney $U$ test results on policy indicator variables between two groups of countries. $\left({ }^{*}<0.10 ;{ }^{* *}<0.05 ; * * * 0.01\right)$.

\begin{tabular}{cccc}
\hline Policy Variable & $\begin{array}{c}\text { Above Median Eff. } \\
(\mathbf{n}=\mathbf{1 3})\end{array}$ & $\begin{array}{c}\text { Equal/Below Median Eff. } \\
(\mathbf{n}=\mathbf{1 6})\end{array}$ & $p$ Value \\
\hline User choice of insurers & $0.500(.877)$ & $1.938(2.081)$ & $0.053^{*}$ \\
Private Provision & $2.223(1.501)$ & $3.069(1.165)$ & 0.219 \\
Regulation of provider prices & $4.150(1.126)$ & $4.081(.983)$ & 0.313 \\
User information & $0.479(.836)$ & $1.538(1.418)$ & $0.039 *$ \\
Regulation of workforce \& equipment & $2.850(1.674)$ & $2.800(.991)$ & 0.617 \\
Choice among providers & $4.407(2.114)$ & $4.169(2.033)$ & 0.271 \\
Gatekeeping & $2.071(2.386)$ & $3.750(2.266)$ & 0.114 \\
Budget Constraint & $3.071(2.057)$ & $2.563(2.065)$ & 0.322 \\
Decentralization & $1.193(1.743)$ & $2.438(1.567)$ & $0.003 * *$ \\
Consistency & $4.386(1.501)$ & $4.531(1.564)$ & 0.757 \\
\hline
\end{tabular}

Table 5 shows the empirical results of the Tobit regression model. The three health care policy indicators of user choice of insurers (UCI) and user information (UI) were statistically significant at the 0.01 significance level and decentralization (DC) was statistically significant at the 0.05 significance level. In addition, all three health care policy indicators were found to have a negative impact on health care efficiency. Note that the policy indicator variables were converted into logarithmic scales.

Table 5. Tobit regression results. $(* *<0.05 ; * * * 0.01)$.

\begin{tabular}{ccccc}
\hline Variable & Coefficient & Std. Error & z-Statistic & $p$-Value \\
\hline Constant & 0.934 & 0.041 & 22.812 & $2 \times 10^{-16}$ \\
UCI & -0.074 & 0.028 & -2.65 & $0.00812^{* * *}$ \\
UI & -0.110 & 0.035 & -3.15 & $0.00165^{* * *}$ \\
DC & -0.064 & 0.030 & -2.16 & $0.03049^{* *}$ \\
\hline
\end{tabular}

\section{Discussion}

The main contents of our analysis are as follows: (1) the Social Health Insurance system showed the least efficiency score on average when compared to other types of systems but we could not find evidences of a statistically significant difference of healthcare efficiency between the four types of healthcare system; and (2) through the Tobit Regression, user information (quality on the prices of various health care services), user choice (for basic insurance coverage), and decentralization (to sub-national governments) showed that these three policy factors had a negative impact on the efficiency of healthcare systems.

Joumard et al. [31] used six classification types (based on cluster analysis) and could not also find evidence of a healthcare system that systematically performed better than another. However, countries with Social Health Insurance, except Luxembourg, showed a remarkably low efficiency score (Austria 34th, Germany 35th, Switzerland 28th). In Kujawska's work [36] with 2010 data, Austria (29th out of 31 countries), Germany (28th), and Switzerland (25th) were considered inefficient. In Retzlaff-Roberts et al.'s work [14] with 2000 data, Austria, Germany, and Switzerland were also among the inefficient group (eight countries).

In Austria, Germany, and Switzerland, societal actors rather than the state are in charge of both regulating and financing the healthcare system, which means being less centralized and having less robust regulation than other systems. Wagstaff [37] pointed out that due to insufficient regulation, the costs of collecting revenues are high and therefore the cost efficiency to deliver healthcare service may be poor. He further added that non-enrollment and evasion exacerbated healthcare financing 
under healthcare systems such as those in Austria, Germany, and Switzerland. This is because in those systems, tax financing is limited and health expenditure is mostly financed via individual funds [38]. However, Luxembourg, the only country other than those countries that have societal actors taking charge of regulation and financing, showed the highest efficiency when compared to any other country. Luxembourg only has 2.86 of practicing physicians per capita (23rd), but showed a 356.14 infant survival rate (9th), and a 85.2 year life expectancy (6th). We found that Luxembourg is a single-payer system while Austria, Germany, and Switzerland are multi-payer systems [39]. This difference can be one of the factors involved in the efficiency gap.

We have shown that a high level of user choice (for basic insurance coverage) may cause inefficiency in the healthcare system. Several studies have suggested that more choice may not lead to positive results regarding state welfare. According to Cutler and Reber [40], increased health insurance competition (such as a voucher-type system) means that the various choices available may stimulate significant adverse selection and result in a negative net effect in the end. Meanwhile, Botti and Iyengar [41] argued that people make worse choices as a set of options increases due to psychological mechanisms such as information overload and preference uncertainty, especially when it comes to social welfare. For these reasons, a high level of user choice may lead to the bad choices of consumers and result in inefficiency.

We also found that a high level of user information may decrease efficiency in healthcare systems. It clearly contradicts the conclusion of Joumard et al. [31], who mentioned that better user information would be an option to reform the healthcare system. This might be because Joumard et al. [31] used a different approach (principal component analysis) other than DEA. Additionally, as they also mentioned, the effect of better user information may be limited by the difficulty in understanding the information. For example, Hanoch et al. [42] pointed out that a wide range of drug plan choices may lead to disadvantageous choices, especially to old people. We concluded that the relationship between user information and healthcare system efficiency needs to be further investigated.

We also observed that multi-payer systems such as those in Switzerland, the Netherlands, and Germany showed high levels of user choice (6.0, 4.0, 6.0 each, respectively) and showed very low levels of efficiency scores (22nd, 26th, 29th each, respectively). However, single-payer systems such as Luxembourg, and Greece showed relatively low levels of user choice (0.0, 2.0 each, respectively) and showed the highest efficiency score (1st, 2nd each, respectively). That is, a high level of user choice may mean that there are multiple insurers in the country and people have more freedom to choose them. Although the 'single-payer or multi-payer' issue has long been controversial [43], it is said that the single-payer system can effectively manage risk and make whole health expenditure at a national level easily controllable [44] and multi-payer systems can cost more compared to financially integrated systems [45]. This may partly be because the greater administrative cost is associated with fewer insurers and more claims-processing facilities [46], and the standardization of health service in single-payer system is also the key to reduce administrative costs [47]. It is also pointed out that the administrative efficiency of the US healthcare system has been exacerbated due to insurance overheads, etc. [48]. Therefore, we can demonstrate that a high level of user choice is likely to lead to inefficiency in the healthcare system due to its close relationship with a multi-payer system.

Decentralization (to sub-national governments) also has a negative impact on the efficiency of healthcare systems. In fact, decentralization and centralization have long been controversial in health policy debate [49]. Nowadays, re-centralization has been a trend in health policy since the start of the 21st century after countries like Finland and Norway showed increased disparities between central and local control [50]. This is partly because a national health system might lose cohesiveness due to the decentralized system as Mosca [51] pointed out previously. That is, the achievement of national priorities can be more difficult as the local units exercise their authority for specific interests [52]. 


\section{Conclusions}

In this study, the efficiency of the healthcare system was estimated using the DEA bootstrap technique. Moreover, it was shown that there were no significant differences in efficiency according to the classification of OECD healthcare systems. Next, the Tobit regression analysis also suggested that user choice, and decentralization had a negative impact on health care efficiency.

It is meaningful that this paper compared the efficiency of healthcare systems according to the recent five type classification published in 2013. Furthermore, there have been many studies analyzing the determinants of the efficiency of healthcare systems. However, most have focused on population behavior, socioeconomic factors, and environmental factors, etc. We used multiple health policy factors in analyzing the DEA results and found a correlation with efficiency for the first time.

However, one clear limitation was that we only considered quantitative data in the measurement of healthcare system performance, which do not reflect the qualitative factors of healthcare. It is said that quantified indicators of healthcare quality such as the global data of the satisfactory level of healthcare consumers need to be further developed in the future.

Secondly, improving efficiency does not necessarily mean improving the healthcare system since there may be a trade-off between efficiency and equity. Therefore, this requires further research into detailed health policies that improve efficiency and do not sacrifice equity at the same time.

It has also been pointed out that the sample of the Social Health Insurance system in particular consisted of only four countries, which may be too small for statistical inference. In addition, five types of healthcare system may be insufficient to account for all varieties of healthcare systems worldwide. Further study with more countries and more subdivided classification of healthcare system is required in the future.

Finally, there have been some studies about policy making for smart cities [53-55]. Visvizi et al. [53] set a starting point for policy making integration for smart healthcare services, and Spruit and Lytras [54] applied data science in healthcare for data driven policy making in the healthcare domain. Furthermore, Lytras and Visvizi [55] explored the integration of smart healthcare to smart cities strategies. These studies point to new avenues of healthcare research, so further research should consider this new concept for healthcare and smart cities.

Author Contributions: Conceptualization, S.L.; Data curation, S.L.; Project administration, C.K.; Supervision, C.K.; Writing—original draft, S.L.; Writing-review \& editing, C.K.

Funding: This work was supported by Incheon National University Research Grant in 2018.

Conflicts of Interest: The authors declare no conflict of interest.

\section{References}

1. Marten, R.; McIntyre, D.; Travassos, C.; Shishkin, S.; Longde, W.; Reddy, S.; Vega, J. An assessment of progress towards universal health coverage in Brazil, Russia, India, China, and South Africa (BRICS). Lancet 2014, 384, 2164-2171. [CrossRef]

2. Saltman, R.B. Decentralization, re-centralization and future European health policy. Eur. J. Public Health 2008, 18, 104-106. [CrossRef] [PubMed]

3. Victoor, A.; Delnoij, D.M.; Friele, R.D.; Rademakers, J.J. Determinants of patient choice of healthcare providers: A scoping review. BMC Health Serv. Res. 2012, 12, 272. [CrossRef] [PubMed]

4. Fotaki, M. Patient choice in healthcare in England and Sweden: From quasi-market and back to market? A comparative analysis of failure in unlearning. Public Adm. 2007, 85, 1059-1075. [CrossRef]

5. Horton, R.; Das, P. Universal health coverage: Not why, what, or when-But how? Lancet 2015, 385, 1156-1157. [CrossRef]

6. Vuong, Q.H. Sociodemographic factors influencing Vietnamese patient satisfaction with healthcare services and some meaningful empirical thresholds. Iran. J. Public Health 2018, 47, 119-126. 
7. Murray, C.J.L.; Frenk, J. A WHO Framework for Health System Performance Assessment; Global Programme on Evidence for Health Policy Discussion Paper No. 6; World Health Organization: Geneva, Switzerland, 1999.

8. Farrell, M.J. The measurement of productive efficiency. J. R. Stat. Soc. Ser. A 1957, 120, 253-278. [CrossRef]

9. Evans, D.B.; Tandon, A.; Murray, C.J.; Lauer, J.A. The comparative efficiency of national health systems in producing health: An analysis of 191 countries. World Health Organ. 2000, 29, 1-36.

10. Hollingsworth, B. The measurement of efficiency and productivity of health care delivery. Health Econ. 2008, 17, 1107-1128. [CrossRef]

11. Evans, D.B.; Tandon, A.; Murray, C.J.; Lauer, J.A. Comparative efficiency of national health systems: Cross national econometric analysis. BMJ 2001, 323, 307-310. [CrossRef]

12. Gravelle, H.; Jacobs, R.; Jones, A.M.; Street, A. Comparing the efficiency of national health systems: A sensitivity analysis of the WHO approach. Appl. Health Econ. Health Policy 2003, 2, 141-148. [PubMed]

13. Greene, W. Distinguishing between heterogeneity and inefficiency: Stochastic frontier analysis of the world health organization's panel data on national health care systems. Health Econ. 2004, 13, 959-980. [CrossRef] [PubMed]

14. Retzlaff-Roberts, D.; Chang, C.F.; Rubin, R.M. Technical efficiency in the use of health care resources: A comparison of OECD countries. Health Policy 2004, 69, 55-72. [CrossRef] [PubMed]

15. Bhat, V.N. Institutional arrangements and efficiency of health care delivery systems. Eur. J. Health Econ. 2005, 6, 215-222. [CrossRef]

16. Wranik, D. Healthcare policy tools as determinants of health-system efficiency: Evidence from the OECD. Health Econ. Policy Law 2012, 7, 197-226. [CrossRef] [PubMed]

17. Hadad, S.; Hadad, Y.; Simon-Tuval, T. Determinants of healthcare system's efficiency in OECD countries. Eur. J. Health Econ. 2013, 14, 253-265. [CrossRef]

18. Banker, R.D.; Charnes, A.; Cooper, W.W. Some models for estimating technical and scale inefficiencies in data envelopment analysis. Manag. Sci. 1984, 30, 1078-1092. [CrossRef]

19. Simar, L.; Wilson, P.W. Estimation and inference in two-stage, semi-parametric models of production processes. J. Econom. 2007, 136, 31-64. [CrossRef]

20. Dyson, R.G.; Allen, R.; Camanho, A.S.; Podinovski, V.V.; Sarrico, C.S.; Shale, E.A. Pitfalls and protocols in dea. Eur. J. Oper. Res. 2001, 132, 245-259. [CrossRef]

21. Simar, L.; Wilson, P.W. A general methodology for bootstrapping in non-parametric frontier models. J. Appl. Stat. 2000, 27, 779-802. [CrossRef]

22. Ruggiero, J. Non-discretionary inputs in data envelopment analysis. Eur. J. Oper. Res. 1998, 111, 461-469. [CrossRef]

23. Asandului, L.; Roman, M.; Fatulescu, P. The efficiency of healthcare systems in Europe: A data envelopment analysis approach. Procedia Econ. Financ. 2014, 10, 261-268. [CrossRef]

24. Vuong, Q.H.; Ho, T.M.; Nguyen, H.K.; Vuong, T.T. Healthcare consumers' sensitivity to costs: A reflection on behavioural economics from an emerging market. Palgrave Commun. 2018, 4, 70. [CrossRef]

25. Crémieux, P.Y.; Ouellette, P.; Pilon, C. Health care spending as determinants of health outcomes. Health Econ. 1999, 8, 627-639. [CrossRef]

26. Nixon, J.; Ulmann, P. The relationship between health care expenditure and health outcomes. Eur. J. Health Econ. 2006, 7, 7-18. [CrossRef] [PubMed]

27. Trzeciak, S.; Rivers, E. Emergency department overcrowding in the United States: An emerging threat to patient safety and public health. Emerg. Med. J. 2003, 20, 402-405. [CrossRef]

28. Afonso, A.; St Aubyn, M. Non-Parametric Approaches to Education and Health Expenditure Efficiency in OECD Countries; OECD: Paris, France, 2004.

29. Böhm, K.; Schmid, A.; Götze, R.; Landwehr, C.; Rothgang, H. Five types of OECD healthcare systems: Empirical results of a deductive classification. Health Policy 2013, 113, 258-269. [CrossRef]

30. OECD. The Reform of Health Care Systems; Organization of Economic Cooperation and Development: Paris, France, 1994.

31. Joumard, I.; André, C.; Nicq, C. Health Care Systems: Efficiency and Institutions; OECD Publishing: Paris, France, 2010.

32. Horrace, W.C.; Oaxaca, R.L. Results on the bias and inconsistency of ordinary least squares for the linear probability model. Econ. Lett. 2006, 90, 321-327. [CrossRef]

33. Anscombe, F. Graphs in statistical analysis. Am. Stat. 1973, 27, 17-21. 
34. Peduzzi, P.; Concato, J.; Kemper, E.; Holford, T.R.; Feinstein, A.R. A simulation study of the number of events per variable in logistic regression analysis. J. Clin. Epidemiol. 1996, 49, 1373-1379. [CrossRef]

35. Vittinghoff, E.; McCulloch, C.E. Relaxing the rule of ten events per variable in logistic and cox regression. Am. J. Epidemiol. 2007, 165, 710-718. [CrossRef] [PubMed]

36. Kujawska, J. Measurement of healthcare system efficiency in OECD countries. Quant. Methods Econ. 2015, $16,23-32$.

37. Wagstaff, A. Social health insurance reexamined. Health Econ. 2010, 19, 503-517.

38. Normand, C.; Busse, R. Social health insurance financing. In Funding Health Care: Options for Europe; Open University Press: Philadelphia, PA, USA, 2002; Volume 59.

39. Pearson, M.; Colombo, F.; Murakami, Y. Universal Health Coverage and Health Outcomes: Final Report; OECD Publishing: Paris, France, 2016.

40. Cutler, D.M.; Reber, S.J. Paying for health insurance: The trade-off between competition and adverse selection. Q. J. Econ. 1998, 113, 433-466. [CrossRef]

41. Botti, S.; Iyengar, S.S. The dark side of choice: When choice impairs social welfare. J. Public Policy Mark. 2006, 25, 24-38. [CrossRef]

42. Hanoch, Y.; Rice, T.; Cummings, J.; Wood, S. How much choice is too much? The case of the Medicare prescription drug benefit. Health Serv. Res. 2009, 44, 1157-1168. [CrossRef] [PubMed]

43. Dave, D. Health care: Multi-payer or single-payer? East. Econ. J. 2017, 43, 180-182. [CrossRef]

44. Hussey, P.; Anderson, G.F. A comparison of single-and multi-payer health insurance systems and options for reform. Health Policy 2003, 66, 215-228. [CrossRef]

45. Docteur, E. Towards High-Performing Health Systems: The OECD Health Project; OECD: Paris, France, 2004.

46. Woolhandler, S.; Campbell, T.; Himmelstein, D.U. Costs of health care administration in the United States and Canada. N. Engl. J. Med. 2003, 349, 768-775. [CrossRef]

47. Cutler, D.; Wikler, E.; Basch, P. Reducing administrative costs and improving the health care system. N. Engl. J. Med. 2012, 367, 1875-1878. [CrossRef]

48. Woolhandler, S.; Himmelstein, D.U. The deteriorating administrative efficiency of the US health care system. N. Engl. J. Med. 1991, 324, 1253-1258. [CrossRef]

49. Costa-Font, J.; Greer, S. Federalism and Decentralization in European Health and Social Care; Springer: Berlin, Germany, 2016.

50. Jacobs, R.; Smith, P.C.; Street, A. Measuring Efficiency in Health Care: Analytic Techniques and Health Policy; Cambridge University Press: Cambridge, UK, 2006; ISBN 1139456873.

51. Mosca, I. Is decentralisation the real solution? A three country study. Health Policy 2006, 77, 113-120. [CrossRef]

52. Darras, C. Local health services: Some lessons from their evolution in Bolivia. Trop. Med. Int. Health 1997, 2 , 356-362. [CrossRef]

53. Visvizi, A.; Lytras, M.D.; Damiani, E.; Mathkour, H. Policy making for smart cities: Innovation and social inclusive economic growth for sustainability. J. Sci. Technol. Policy Manag. 2018, 9, 126-133. [CrossRef]

54. Spruit, M.; Lytras, M. Applied Data Science in Patient-centric Healthcare. Telematics Inform. 2018, 35, 643-653. [CrossRef]

55. Lytras, M.D.; Visvizi, A. Who Uses Smart City Services and What to Make of It: Toward Interdisciplinary Smart Cities Research. Sustainability 2018, 10, 1998. [CrossRef]

(C) 2018 by the authors. Licensee MDPI, Basel, Switzerland. This article is an open access article distributed under the terms and conditions of the Creative Commons Attribution (CC BY) license (http://creativecommons.org/licenses/by/4.0/). 